\title{
Práticas avaliativas: reflexões acerca da inserção da saúde bucal na Equipe de Saúde da Família
}

Evaluation practices: reflections on the integration of oral health in the Family Health Team

Ana Claudia M. Pimenta Giudice', Luciane Maria Pezzato², Carlos Botazzo³

Mestre em Saúde Coletiva pela Universidade de Campinas (UNICAMP) - Campinas (SP), Brasil. Cirurgiã-Dentista da Secretaria Municipal de Saúde de Campinas - Campinas (SP), Brasil.

anacmpg@yahoo.com.br

2 Doutora em Saúde Coletiva e Mestre em Educação pela Universidade de Campinas (UNICAMP) - Campinas (SP), Brasil. Professora da Pontifícia Universidade Católica de Campinas (PUC-Campinas) - Campinas (SP), Brasil.

lupezzato@yahoo.com.br

${ }^{3}$ Doutor em Saúde Coletiva pela Universidade de Campinas (UNICAMP) - Campinas (SP), Brasil. Professor do Departamento de Odontologia Social da Universidade de São Paulo (USP) - São Paulo (SP), Brasil.

cbotazzo@hotmail.com
RESUMO O objetivo deste estudo foi apresentar algumas ferramentas de avaliação em saúde, visando a contribuir para a obtenção de dados qualitativos e estimular a cultura avaliativa nos serviços. Analisou-se o processo de trabalho de uma equipe de referência da Equipe de Saúde da Família (ESF), utilizando entrevistas semiestruturadas e grupos focais. Para análise, fundamentou-se no programa de 'Avaliação para Melhoria da Qualidade da Estratégia Saúde da Família' e nos critérios de avaliação de 'Quarta Geração'. As ações consideradas apresentaram avanços significativos, sendo as propostas assimiladas de forma singular pelos profissionais, e perceberam-se poucos indícios de empoderamento pelos usuários.

PALAVRAS CHAVE: Práticas Avaliativas em Saúde; Serviços de Saúde; Saúde Bucal.

\begin{abstract}
The objective of this study was to present some assessment tools for health, aiming to contribute to the achievement of qualitative data and foster evaluative cultures in services. We analyzed the work process of a team of reference of the Family Health Team (FHT), using semi-structured interviews and focus groups. For analysis, this paper was based on the program 'Evaluation for Quality Improvement of the Family Health Strategy' and the assessment criteria of 'Fourth Generation.' The actions considered showed significant progress, being the proposals assimilated by professionals in a peculiar way, and little evidence of empowerment was perceived by users.
\end{abstract}

KEYWORDS: Assessment practices in Health; Health Services; Oral Health. 


\section{Introdução}

Saúde não representa a mesma coisa para todas as pessoas. Dependerá da época, do lugar, da classe social. Dependerá de valores individuais, dependerá de concepçóes científicas, religiosas, filosóficas. O mesmo pode ser dito das doenças. (SCLIAR, 2007).

Ao longo dos tempos, as concepçôes e as práticas de saúde e de doença evoluíram, seguindo diferentes paradigmas. De acordo com Guedes, Nogueira e Camargo Jr., (2006, p. 1100),

\section{[...] a biomedicina experimentou avanços ex-} traordinários na área tecnológica e medicamentosa, mas ainda assim apresenta muitos fracassos na prática clínica, sobretudo no que concerne em o médico lidar com fenômenos subjetivos no individuo que demanda por cuidado.

Assim, segundo os autores, houve uma cisão entre o saber e a prática médica, fragmentando o 'paciente' e seus sintomas subjetivos versus objetivos, fazendo com que "na maioria das vezes, os sintomas subjetivos não são levados em conta, ou mesmo, não se sabe como 'dar conta' deles" (GUEDES; NOGUEIRA; CAMARGO JR., 2006, p. 1095).

Esse paradigma reducionista de prática de saúde vem sendo questionado, pois tem demonstrado pouca resolutividade sob as reais necessidades dos problemas de saúde de boa parte da população. Emerge, deste modo, uma necessidade de se proporem outros caminhos para se pensar e fazer saúde, afetando os modos como os serviços estão organizados (LUZ, 2005; CAMPOS, 2003; CECCIM; MERHY, 2009).

Nessa direção, formas instituintes de atenção à saúde vêm sendo propostas, procurando recuperar o homem como um todo, um ser desejante, inserido numa sociedade, como é o caso do Programa de Saúde da Família (PSF), proposto pelo Ministério da Saúde em 1994, que é uma estratégia por meio da qual se visa a:
[...] aprimorar o funcionamento do Sistema Único de Saúde-SUS, no contexto da elaboração e construção de novas práticas de saúde. Mais que isso, objetiva o rompimento com o modelo hegemônico de atenção à saúde, biomédico, que se mostrou incapaz de atender de forma eficiente às demandas da população. (SANCHEZ; DRUMOND; VILAÇA, 2008).

Para isso, é necessária a eficaz integração entre os profissionais de saúde, os serviços e os usuários. Segundo Souza e Roncalli (2007, p. 2727), o PSF “[...] tem se tornado, nos últimos anos, o principal programa alavancador da reorganização dos serviços na atenção básica”.

Entendemos que a saúde bucal é integrante desse processo, mas merece registro o fato de a incorporação oficial da equipe de saúde bucal no PSF ter ocorrido apenas em 2000, da forma descrita a seguir:

[...] a sua incorporação ao PSF tem sido vista como possibilidade de romper com os modelos assistenciais em saúde bucal excludentes baseados no curativismo, tecnicismo e biologicismo. Isso porque o PSF, de certa forma, tenta romper com a lógica programática desses modelos, visto que não só articula as propostas da vigilância à saúde baseando-se na integralidade, mas também possui como um de seus principios a busca ativa de familias, as quais são consideradas como núcleo social primário. (SOUZA; RONCALLI, 2007, p. 2727-2728).

Entre os anos de 2001 e 2004, a gestão da Secretaria Municipal de Saúde de Campinas (SP) iniciou a implantação do Projeto de Saúde da Família de uma forma singular, com as equipes ampliadas, incluindo a saúde bucal, e o denominou Paidéia.

O Projeto Paidéia propôs como diretrizes a criação do vínculo, a priorização de riscos e a vulnerabilidade sócio-epidemiológica, além da lógica da Clínica Ampliada, que visa a produção de saúde, aliviando sintomas e cuidando das pessoas, curando e reabilitando doentes e suas famílias (CAMPOS, 2000). 
Originou-se, assim, um novo trabalho, que partia em busca de novas práticas e possibilidades, centradas nos usuários e em suas necessidades singulares, incorporando atendimento interdisciplinar, a corresponsabilização e, ainda, um desejo premente de que esta nova forma de atendimento fizesse sentido para o trabalhador, os usuários e a sociedade.

Mesmo com o intuito de provocar mudanças na reorganização dos serviços, esses projetos instituintes ainda encontram grandes desafios em sua implementação, como afirma Bodstein (2002, p. 410):

\section{Apesar das profundas mudanças, o contexto da descentralização no pais é marcado, na grande maioria dos municipios, por uma precariedade e fragilidade estrutural tanto de instalaçóes e capacidade física quanto de recursos humanos e técnicos.}

O Município de Campinas (SP) faz parte dessa realidade, pois encontrou grandes desafios para a implementação desse projeto Paidéia. No que se refere à equipe de saúde bucal, não havia integração com a equipe de saúde da família, mas tal proposta introduziu algumas mudanças significativas não mensuradas, o que gerou uma necessidade de avaliação.

De acordo com o documento técnico 'Avaliação para Melhoria da Qualidade da Estratégia Saúde da Família (AMQESF)', proposto pelo Ministério da Saúde (BRASIL, 2006, p. 9), avaliar significa "[...] formar opiniấo, julgar e emitir juízo de valor sobre determinado assunto". Geralmente, esse tema está relacionado a aspectos negativos, como punição, classificação e eliminaçáo daqueles que não alcançaram determinado resultado, mas vem-se tentando superar esse paradigma, marcado por precedentes históricos e culturais, e utilizar a avaliação como instrumento permanente de consulta para tomada de decisóes de gestores.

Visto dessa forma, este estudo buscou avaliar o processo de trabalho de uma das equipes de referência, de uma Unidade Básica de Saúde, no Município de Campinas (SP), durante a implantação do Projeto Paidéia Saúde da Família, e apresentar algumas ferramentas de avaliação em saúde disponíveis na literatura, visando a contribuir para a obtenção de dados qualitativos e estimular a cultura avaliativa nos serviços de saúde.

\section{Metodologia}

Utilizou-se a metodologia da pesquisa qualitativa e, por meio de entrevistas semiestruturadas (com usuários) e grupos focais (com profissionais de saúde), realizou-se a coleta de dados, no sentido histórico-social, buscando-se informaçóes do período vivenciado pelos próprios atores. A entrevista semiestruturada "obedece a um roteiro apropriado fisicamente por ter apoio claro na sequencia de questóes", possibilitando abordagem segura para que o investigador explore todos os objetivos propostos (MINAYO, 2006, p. 267). Já o grupo focal é uma "técnica de pesquisa que utiliza as sessóes grupais como um dos foros facilitadores de expressão de características psicossociológicas e culturais" (WESTPHAL; BÓGUS; FARIA, 1996, p. 473).

Os dois grupos focais foram realizados na própria unidade de saúde, em horário de trabalho, contando com a participação de oito profissionais em cada um deles. Buscou-se discutir os processos de trabalho, as lembranças e as vivências do período de implantação do projeto Paidéia naquela unidade. $\mathrm{O}$ termo de consentimento livre e esclarecido foi assinado por todos, sendo que o projeto da pesquisa foi aprovado pelo Comitê de Ética em Pesquisa da Faculdade de Odontologia da UNICAMP (FOP), protocolo 203/2006.

Os trabalhadores participaram voluntariamente e a pesquisadora se comprometeu em realizar a devolutiva para que todos conhecessem os resultados desta investigação.

De acordo com Gatti (2005), o trabalho com grupos focais permite compreender processos de construção da realidade por determinados grupos sociais. Possibilita compreender, também, práticas cotidianas, açôes e reaçôes, fatos e eventos, comportamentos e atitudes, constituindo uma técnica importante para o conhecimento de representaçóes, percepçōes, crenças, hábitos, valores, restrições, 
preconceitos, linguagens e simbologias prevalentes no trato de uma dada questão por pessoas que partilham alguns traços em comum relevantes para o estudo do problema verificado.

As entrevistas semiestruturadas foram realizadas com usuários, em visitas domiciliares, pela investigadora juntamente com a enfermeira e o agente comunitário de saúde (ACS) da equipe de referência. Das 82 casas visitadas, 76 usuários encontrados se dispuseram a colaborar com a pesquisa. Estes estavam vinculados à equipe em questão e haviam se envolvido integralmente com as açôes propostas. Participaram usuários de ambos os sexos e todos tinham mais de 18 anos de idade.

A formulação dos roteiros das entrevistas baseouse nos instrumentos de "Avaliação da Melhoria da Qualidade da Estratégia Saúde da Família”, propostos pelo Ministério da Saúde em 2005. Estes instrumentos têm o objetivo de fomentar o monitoramento e a avaliaçáo dos estágios de qualidade da Estratégia Saúde da Família, além de apoiar o desenvolvimento das iniciativas e contribuir para a construção da cultura avaliativa nos serviços (BRASIL, 2005).

Os roteiros das entrevistas e dos grupos focais constaram de questóes fechadas para abordar os dados pessoais, profissionais e grau de escolaridade, além de questóes abertas no sentido de obter as lembranças de como era a percepção da organizaçáo do trabalho da saúde bucal antes e após a implantação do Paidéia, bem como, se havia ocorrido alguma diferença em suas vidas neste período.

As 92 falas (total de usuários que responderam ao questionário e funcionários que participaram dos grupos focais) foram gravadas e transcritas integralmente, e posteriormente agregadas por assuntos/temas, já que ambos os roteiros abordaram as mesmas questóes. Utilizou-se a transcrição real e não modificada das entrevistas e das falas nos grupos focais, com o objetivo de apreender o ponto de vista dos sujeitos da pesquisa, sem julgamentos ou pré-conceitos por parte do pesquisador.

Minayo (2006) afirmou que, em uma abordagem qualitativa, o critério de amostragem não é numérico. Assim, houve menos preocupaçáo com a generalização e mais com o aprofundamento e a abrangência da compreensão.
Para a análise e a discussão dos resultados, foram desenvolvidas reflexóes baseadas nos trabalhos de Guba e Lincoln (1989) - 'Avaliação de Quarta Geração' - e nos instrumentos de AMQESF (BRASIL, 2006). Essas ferramentas complementaram-se, visto que possibilitaram a participação de todos os atores envolvidos no processo avaliativo.

A 'Avaliação de Quarta Geração' avança sobre a de 'Terceira Geração' - que opera com as categorias de estrutura, processo e resultados - porque, além dessas, inclui os sujeitos envolvidos: planejadores, educadores, sujeitos cognoscentes (profissionais de saúde e usuários do sistema), que realizam, interagem e se interessam por diferentes e até contrastantes razões no processo de aprendizado e mudança (SMEKE, 2007). Tomou-se, portanto, como um desafio trabalhar com os diferentes grupos de usuários e de funcionários da unidade, além dos próprios membros da equipe de referência em questão, a fim de avançar no processo avaliativo, não tendo sido possível, naquele momento, envolver os gerentes, de nível central e local.

Os instrumentos de AMQESF
privilegiam e enfatizam os elementos de pro- cesso, especialmente os processos de trabalho, os quais oferecem possibilidades amplas e acessi- veis de intervenção quando os problemas são identificados. (BRASIL, 2006, p. 25).

No que se refere à prestação de serviços de saúde, foram avaliados segundo os aspectos organizativo, técnico-científico e a relação interpessoal (BRASIL, 2006, p. 25).

Para fins desta proposta, define-se qualidade em saúde como o grau de atendimento a padróes de qualidade estabelecidos frente a normas e protocolos que organizam as açóes práticas, bem como frente aos conhecimentos técnicos e científicos atuais. Para que os padróes sejam legitimados e tenham adesão dos profissionais, além de aplicabilidade para uso rotineiro dentro dos serviços de saúde, devem reunir um conjunto de características básicas, tais como: abrangência, e sensibilidade para evidenciar mudanças e facilidade na aplicação. Foram considerados, ainda, o atendimento 
às necessidades de saúde percebidas e as expectativas dos usuários, suas famílias, bem como a resposta às necessidades definidas tecnicamente. Estes dois processos possibilitaram verificar o estágio de desenvolvimento alcançado pela equipe em questão.

\section{Diagnóstico da organização, da estrutura, do funcionamento e do processo antes da implantação do projeto Paidéia}

Seguindo os preceitos de Donabedian, os instrumentos utilizados possibilitaram que os sujeitos envolvidos nesta pesquisa, no momento do grupo focal ou das entrevistas, refletissem acerca da organização (estrutura), do funcionamento (processo) e dos resultados (BRASIL, 2006) de seus processos de trabalho.

$\mathrm{Na}$ unidade de saúde pesquisada, a organização das atividades de saúde bucal, até a implantação do novo modelo, era precária, e o processo de trabalho traduzia um viés característico da grande maioria dos serviços públicos e privados, ou seja, prática hegemônica, tecnicista e biologicista dos profissionais de saúde; ausência de planejamento estratégico e do trabalho em equipe interdisciplinar e multiprofissional; e atenção individualizada conduzida pela 'queixa-conduta', limitada às vagas de urgência, sem avaliação e acolhimento das necessidades dos usuários, equipamento e insumos disponíveis. Enfim, realizava-se uma 'clínica degradada', que impingia uma lógica de submissão e personificava a doença. De acordo com Campos (2003), a 'clínica degradada' é marcada por interesses de qualquer natureza, sejam eles econômicos, políticos ou ideológicos, numa perspectiva mercadológica, capitalista, que não considera a necessidade de saúde em sua práxis. Cria, em seu entorno, um espaço autoritário de saberes e de poderes em que o usuário fica sujeitado.

Tal unidade de saúde não estava inserida em um sistema funcional e resolutivo. Os profissionais relacionavam-se apenas informalmente e socialmente sem agregar saberes, sem espaços para socializar suas experiências, discutir casos, pendências, sucessos/insucessos, possibilidades.

As vagas, distribuídas aleatoriamente e por ordem de chegada às filas, geravam grande rotatividade, sem criação de vínculo, produzindo condutas terapêuticas fragmentadas, emergenciais.

Com frequência, devido ao caráter infeccioso das principais doenças da cavidade bucal, bem como a racionalidade biomédica presente no modo de produção do cuidado em saúde, limitando-se 'a queixa-conduta', além da dificuldade no acesso aos serviços de média e alta complexidade, os usuários acabavam tendo sua saúde comprometida.

Conforme afirmam Botazzo e Barros (2009):

No SUS, a rotina clinica permanece centrada, em geral, no tratamento efetuado mecanicamente como linha de produção: o cirurgiāo-dentista recebe usuários, em sua maioria jovens, com cavitaçóes e raizes residuais, e os libera com restauraçôes e suturas. $\mathrm{Na}$ lógica das açóes programáticas, curetam-se cavidades $e$ restauram-se dentes conferindo um tratamento completado. E os usuários entram mudos e saem calados.

Corroborando este contexto, citamos algumas falas gravadas em entrevistas:

Cansei de 'vim' no posto e não ter vaga nem pra mim, nem pros meus filhos... É, minha filha, pobre é assim mesmo... Por isto que a gente fica sem os 'dente'. (A. S. M., 55 anos, sexo feminino, usuária do C. S.).

Este buraco aqui no fundo é um inferno... Tudo que eu como vai lá dentro... Eu já fui 'no' posto umas dez 'vez', mas eu chego bem cedo e mesmo assim nâo consigo vaga... Tem sempre um cartaz dizendo quantas vagas vai ter naquele dia e a hora que eu chego já tem muita gente na minha frente... (M. A. P., 37 anos, sexo feminino, usuária do C. S.).

A cultura do senso comum e o 'conformismo' impediam que os usuários (e também alguns profissionais) interrogassem o serviço, fato que acarretava aumento da naturalização das perdas sociais, econômicas, afetivas 
e políticas, dentre outras. Essa análise converge para as afirmações de Souza (2004), que enfatiza que os usuários - e, entendemos também, muitos profissionais - fazem um consumo acrítico daquilo que é ofertado, conforme constatou-se na fala de uma usuária entrevistada:

Eu vou lá (ao C. S.) desde que meu neném nasceu e dou as vacinas e passo na pediatra... Ela é boazinha... Diz tudo que eu tenho que fazer... (M. A. C., 27 anos, sexo feminino, usuária do C. S.).

Existe um consenso em torno da necessidade de formação humanística de profissionais de saúde. As diversas falas também revelaram, repetidamente, o quanto é fundamental o desafio para serem alcançadas a integralidade e a humanização das práticas que não estão contidas nos currículos universitários, mas, sim, que são intrínsecas (ou não) aos indivíduos que fizeram opção pela carreira da saúde. O comentário a seguir ratifica essa observação.

Quando eu entrei aqui, só conhecia o mundo da faculdade, acadêmico... Nunca tinha o remédio que eu aprendi a prescrever. Os casos são tão cabeludos que a gente não sabe nem por onde começar... A gente chega cheia de ideias e achando que vai conseguir resolver tudo, mas a realidade é muito diferente dos livros e de dentro do hospital, onde a gente tem de tudo... (M. L. T., sexo feminino, funcionária do C. S. - pediatra).

Foi percebido que o enfoque curativo das doenças constituía-se em visão distorcida da realidade e da necessidade do usuário (CORDÓN, 1997). Havia, pontualmente, um ou outro profissional que se preocupava e se incomodava com a maneira assistencial, paternalista e viciada do modelo de atenção prestado.

Cordón (1997, p. 560) já afirmava que o primeiro elemento da agenda dos trabalhadores em saúde coletiva "constitui o saber de que o dentista sozinho não pode resolver os problemas que requerem uma equipe de saúde bucal integrada à equipe de saúde do SUS”.
Chamamos a atenção, também, para a integração com a comunidade a ser assistida, pois se entende que, sem a participação do controle social, nenhuma proposta consegue legitimar-se no cotidiano dos serviços de saúde.

\section{O projeto Paidéia como nova proposta instituinte}

Em 2001, a Secretaria Municipal de Saúde de Campinas iniciou a implantação do Programa Paidéia Saúde da Família de uma forma singular, com as equipes ampliadas - incluindo pediatra e ginecologista, além de contar com o matriciamento de outros profissionais, como psiquiatra, psicólogo, terapeuta ocupacional e nutricionista, dentre outros -, de acordo com as necessidades de cada unidade de saúde. Houve uma capacitaçáo, seguindo os protocolos de implantação do PSF para toda a rede municipal, com cerca de 180 horas-aula.

Originou-se, assim, um novo trabalho, que partia em busca de novas possibilidades e práticas centradas nos usuários e nas suas necessidades singulares.

Tal programa introduzia, entre os principais objetivos, a atuação por equipe de referência, o acolhimento dos usuários com criação de vínculo e a responsabilização pela população adstrita. Para que esses objetivos fossem alcançados, foi proposto que os profissionais operassem segundo uma ótica que integrasse aspectos sociais e subjetivos à formação biológica clássica, que, necessariamente, deveria ser modificada. A ideia era que houvesse uma ampliação da clínica, respeitando o 'núcleo' de cada profissão, incorporando-se novos conhecimentos, visto que passariam a atuar em 'campos' mais amplos, voltados à inter e à transdisciplinaridade.

Esses conceitos-ferramentas propostos por Campos (2006, p. 249) podem, resumidamente, ser definidos da seguinte forma:

\section{[...] o núcleo demarcaria a identidade de uma área de saber e de prática profissional; e o campo, um espaço de limites imprecisos onde cada disciplina ou profissão buscariam, em ou- tras, apoio para cumprir suas tarefas teóricas e práticas.}


De acordo com o processo de territorialização da unidade de saúde onde foi desenvolvida esta pesquisa, foram estabelecidas três equipes de referência ampliadas. A equipe objeto desta pesquisa era composta por uma cirurgiā-dentista, uma auxiliar de saúde bucal (ASB), três médicas (generalista, pediatra e ginecologista), uma enfermeira, quatro auxiliares de enfermagem e quatro ACS.

Em janeiro de 2002, seguindo as diretrizes do Paidéia, essa equipe começou a reunir-se com o propósito de repensar seu processo de trabalho, a fim de propor mudanças. A ideia era conhecer de perto as condiçóes de moradia, reconhecer líderes nas regióes, apresentar os componentes da equipe que iriam, a partir de entáo, se corresponsabilizar pelo cuidado em saúde e convidar a população residente nessas áreas para a 'formação da roda'. O Método da Roda, proposto por Campos (2000), objetiva a constituição de coletivos organizados, o que implica construir capacidade de análise e de cogestão, para que os agrupamentos lidem tanto com a produção de bens e serviços quanto com sua própria constituição.

Esse movimento, instigado pela capacitação, foi um caminho desafiador, tanto individual como coletivo para a referida equipe, pois, conforme Ceccim e Feuerwerker (2004, p. 43), na formação dos profissionais de saúde sempre se privilegiou "a busca eficiente de evidências ao diagnóstico, cuidado, tratamento, prognóstico, etiologia e profilaxia das doenças e agravos".

\section{Resultados e análises do serviço e das práti- cas através dos dados coletados}

A análise dos dados conduziu-nos a interpretar e tentar compreender os conflitos, as relaçóes e práticas percebidas e vivenciadas nas atividades de saúde desenvolvidas pela equipe de referência.

Esse novo modelo de atenção conseguiu introduzir novos saberes nas práticas dos profissionais que se envolveram com o programa, contribuindo para um maior envolvimento intraequipe e com os usuários, incrementando o compromisso com a promoção de saúde das famílias, além de permitir que a capacidade de saberes e responsabilidades para intervir no processo saúde-doença fossem ampliadas, deixando de ser função exclusiva dos profissionais, mesmo que de maneira singular.

Ilustra esse comentário a seguinte afirmação de Teixeira (2006, p. 48):

\section{[...] o profissional de saúde compromissado com o usuário passa a ter um olhar para além do corpo que está a sua frente [...]. O olhar deve se dirigir para a produção do cui- dado daquele sujeito. Portanto, o profissional que tece o ato de cuidar no seu cotidiano está sempre ampliando suas açôes.}

Como se pode verificar nas falas de alguns profissionais, outro aspecto fundamental destacado, com relação aos aspectos organizativos, foi o baixo investimento da Secretaria de Saúde local na infraestrutura básica, obstáculo para que as equipes tivessem condiçôes de, efetivamente, transformar o modo de atuação, conforme traduzem as falas a seguir:

A fila veio para dentro da unidade... Não tinha mais número limitado de vagas, mas o número de profissionais era o mesmo. (C. M. D. A., sexo feminino, funcionária do $\mathrm{C}$. S. - auxiliar de enfermagem).

Além do tempo, a estrutura física também é ruim. Não tem lugar pros grupos, pra acolher os que chegam... Atende lá fora, no corredor... A demanda aumentou e o espaço é o mesmo. Houve mudança de modelo e náo houve mudança de estrutura. (C. R., sexo feminino, funcionária do C. S. - ACS).

Ouviamos muito que tinhamos que trocar o pneu do carro com ele andando... Até hoje estamos tentando, porque o serviço náo para... Mas existe um risco grande para nós, ocupantes do veículo... (M. L. Z., sexo feminino, funcionária do C. S. - auxiliar de dentista). 
Com relação aos aspectos técnico-científicos, pôde-se perceber que houve resistência de alguns profissionais, e a gestão não estava preparada para lidar com isso. Conflitos interpessoais acabaram interferindo no funcionamento da unidade de saúde e dificultando a implementação do programa, como podemos verificar nas seguintes falas:

O projeto em si é legal, mas poderia ter muito mais resolutividade se houvesse perfil nos integrantes das equipes... (C. M., sexo feminino, funcionária do C. S. - auxiliar de enfermagem).

A gente era só auxiliar e, agora, como a rede não tem estrutura para saúde mental, até psiquiatra a gente tem que ser. (C. M. S. I., sexo feminino, funcionária do C. S. - auxiliar de enfermagem).

Quem era bom profissional, ficou ainda melhor com o trabalho nas equipes, mas quem era ruim, não melhorou nada, muito pelo contrário. (E. S., sexo feminino, funcionária do C. S. - ACS).

Existem profissionais e profissionais com letra maiúscula... (C. S., sexo feminino, funcionária do C. S. - auxiliar de enfermagem)

De uma equipe de quase 40 profissionais na unidade, apenas 16 se dispuseram a vivenciar os grupos focais. Tal fato evidenciou a resistência da maioria em participar de processos de mudanças. Com relação à equipe de saúde bucal, dos dois dentistas e três auxiliares de saúde bucal, somente um dentista e duas auxiliares de saúde bucal participaram dos grupos.

A fim de se reverter esse tipo de problema, o documento de avaliação que se utilizou sugere que

[...] os gestores deveriam instituir uma estratégia de seguimento contínuo e comunicação horizontal com os profissionais para fortalecer os processos exitosos e superar as debilidades operacionais identificadas, garantindo condiçôes de trabalho adequadas. (BRASIL, 2006, p. 39).

Outras diretrizes foram incorporadas, de forma singular, pelos diversos profissionais da equipe, tais como: o acolhimento, a criação de vínculo, a assistência em moldes de clínica ampliada e a potencialidade dos grupos. Estes foram, sem dúvida, grandes avanços conseguidos após a capacitação dos profissionais envolvidos com o novo modelo.

Entende-se que havia necessidade de organização, condução e monitoramento mais eficazes das equipes de trabalho, o que inclui a análise permanente das estratégias de intervenção que deveriam ser negociadas e renegociadas, para se assegurar a continuidade do processo.

Entretanto, sabe-se que, além disso, existe uma questão política,

[...] e como tal poderia ser equacionada com vontade e algum refinamento técnico-administrativo - somos tentados a afirmar, ao lançarmos um olhar mais superficial sobre a medicina, os serviços de saúde e os seus descaminhos. (GUEDES; NOGUEIRA; CAMARGO JR., 2006, p. 1094).

No que se refere aos profissionais da saúde bucal, apesar da revisão da literatura demonstrar que há um avanço significativo que aponta para mudanças nos modos de produzir o cuidado nos serviços de saúde do SUS, constatou-se, neste estudo, que ainda existem profissionais muito resistentes à introdução de novas práticas, conforme se pode verificar a seguir:

Foi muito positivo dividir em equipes porque cada dentista ficou com uma área e 'conhecendo' melhor aquela população... O problema foi que um quis fazer o Paidéia e ir 'na' casa das pessoas, e trazer para tratar aqui no posto. Enfim, foi legal... Mas o outro (dentista) não tinha este perfil e se sentiu sobrecarregado porque 
ficava sozinho aqui no posto... É claro que deu briga, né? (Y. V. R., sexo feminino, funcionária do C. S. - ASB).

Isso se deve a uma cultura historicamente construída, de que o profissional de saúde é autônomo, compreensão para a qual contribui o próprio processo formativo. Quando nos referimos especificamente ao cirurgião-dentista, percebemos que, por ser ele um profissional considerado, ainda, como liberal, conforme apresentado por Freitas (2008), sua prática tem sido simplesmente transferida do consultório particular para os serviços públicos de forma mecânica e acrítica (BOTAZZO, 2005; RONCALLI, 2006).

Pinto e Coelho (2008, p. 324-325), ao se referirem a Dejours, associam essa discussão à gestão, afirmando que:

O grau de liberdade e, em contrapartida, de responsabilidade do trabalhador da saúde em relação às suas açóes é, com muita frequência, maior do que em outros campos. Essa autonomia, no entanto, não é desvinculada da gestão, da organização e dos interesses dos usuários.

Demonstra-se, assim, que foi um grande desafio buscar o impacto da qualidade das açóes realizadas por esta equipe de referência durante a implantação de um novo modelo, considerando-se a pluralidade de suas dimensôes (política, econômica, social e tecnológica) e a singularidade dos atores envolvidos na construção do projeto (indivíduos, famílias, comunidades e profissionais).

\section{Considerações Finais}

A diversidade de problemas de saúde identificados em nossa sociedade exige, de fato, projetos inovadores que superem a prática hegemônica pela qual vem sendo conduzida a atenção à saúde.

A cultura avaliativa vem sendo foco da atençáo do Ministério da Saúde, a fim de se institucionalizar a avaliação na atenção básica. Um dos entraves deve-se, em parte, à formação profissional, conforme apontado por Ceccim e Feuerwerker (2004, p. 42):

A formação dos profissionais de saúde tem permanecido alheia à organização da gestão setorial e ao debate critico sobre os sistemas de estruturação do cuidado, mostrando-se absolutamente impermeável ao controle social sobre o setor, fundante do modelo oficial de saúde brasileiro. As instituiçôes formadoras têm perpetuado modelos essencialmente conservadores, centrados em aparelhos e sistemas orgânicos e tecnologias altamente especializadas, dependentes de procedimentos e equipamentos de apoio diagnóstico e terapêutico.

Outro fator que potencializa tal situação, segundo Pinheiro e Silva Jr, (2008, p. 18), seria que:

[...] já existem evidências de que as equipes de saúde locais têm dificuldades de se apropriar dos processos avaliativos, devido ao desconhecimento de suas abordagens e á sobrecarga de tarefas exigidas pelos próprios programas, principalmente as de coleta de dados. Na maioria das vezes, esses dados não são processados por quem os coleta e nem os resultados das análises chegam a tempo útil para ajudar na reflexão de práticas e na conseqüente mudança necessária.

Diante de tal cenário, cabe aos serviços de saúde pensar a prática avaliativa no sentido de agregar valor' institucional e profissional. Necessita, portanto, responsabilizar-se com a qualificaçáo e a adequação dos seus trabalhadores ao SUS.

Com fundamento em Ceccim e Feuerwerker (2004), entende-se que se faz necessário repensar os quatro pilares de educação permanente: formação profissional, atenção à saúde, gestão e controle social.

No quesito formação profissional, entendemos ser necessário desmistificar o 'status' de profissional de saúde, que leva muitos estudantes a fazerem tal opção pela carreira sem o adequado perfil e sem o conhecimento real do que vem a ser a profissão. 
Com relaçáo à atenção à saúde, o programa em questão foi um dos pilares de sustentação para a inserção de novas práticas desenvolvidas pelos trabalhadores da saúde. $\mathrm{O}$ acolhimento, a criação de vínculo, a assistência em moldes de Clínica Ampliada e a potencialidade dos grupos foram ferramentas incorporadas de forma singular pelos diversos profissionais das equipes.

A limitação de infraestrutura e recursos, e a ausência de valorização adequada dos funcionários foram fatores que dificultaram a manutenção do projeto.

Quanto à gestáo, a diversidade dos problemas encontrados demandaria ações que extrapolassem a autonomia e a governabilidade de usuários e funcionários, mas nem sempre a gestão colocou-se aberta a mudanças, ou mesmo possuía qualificaçóes para lidar com algumas destas situaçóes.

Os desafios para a implementação de um projeto com essas características são grandes, pois envolvem macro e micro políticas do trabalho em saúde. Deste modo, acredita-se que há necessidade de se rever e re- avaliar, continuamente, a prática, para se renegociarem novas diretrizes.

Com relação ao controle social, verificamos que faltou trabalho junto à população usuária do serviço, para que houvesse empoderamento das novas formas de produção de saúde. A explicitação à sociedade das necessidades políticas e das medidas sociais específicas é essencial para o impacto positivo da implantação e da implementação de novos modelos, ou seja, para a obtenção de bons resultados, em que estejam juntas Educação e Cidadania.

Nesse sentido, o modelo em questão e as açóes da equipe estudada, sem dúvida, avançaram ao enfatizarem a Clínica Ampliada e incorporarem açóes de promoção à saúde em que se busca a integração de ações preventivas, curativas e de reabilitação, mesmo que realizada de maneira singular.

A diversidade dos problemas identificados necessitava açôes que extrapolavam a autonomia e a governabilidade de usuários e funcionários, e nem sempre foi possível se fazer instituinte.

\section{Referências}

BOTAZZO, C.; BARROS, R. S. Subjetividade e clínica na Atenção Básica. Narrativas, histórias de vida e realidade social. Ciência \& Saúde Coletiva, Rio de Janeiro, v. 16, n. 11, p. 4337-4348, nov. 2011

BOTAZZO, C. Novas abordagens em saúde bucal. A questão da integralidade. In: GARCIA D. V. (Org.). Novos rumos da saúde bucal: os caminhos da integralidade. Rio de Janeiro: ABO-RJ/ANS/ UNESCO, 2005. p. 43-47.

BRASIL. Ministério da Saúde. Secretaria da Gestão do Trabalho e da Educação na Saúde. Curso de Formação de Facilitadores de Educação Permanente em Saúde. Brasília: Ministério da Saúde, FIOCRUZ, 2005

Secretaria de Atenção à Saúde. Departamento de Atenção Básica. Avaliação para Melhoria da Qualidade da Estratégia Saúde da Família. Brasília: Ministério da Saúde, 2006. v. 1.

BODSTEIN, R. Atenção básica na agenda da saúde. Ciência \& Saúde Coletiva, Rio de Janeiro, v. 7, n. 3, p. 401-412, 2002.

CAMPOS, G. W. S. Um método para análise e cogestão de coletivos. São Paulo: Hucitec, 2000.
______. Subjetividade e administração de pessoal: considerações sobre modos de gerenciar o trabalho em equipes e saúde. In: MERHY, E. E.; ONOCKO CAMPOS, R. (orgs.). Agir em saúde. 2. ed. São Paulo: Hucitec, 2006. p. 229-266.

Uma clínica do sujeito: por uma clínica reformulada e ampliada. In: Saúde Paidéia. São Paulo: Hucitec, 2003. p. 51-67.

CECCIM, R. B.; FEVERWERKER, L. O quadrilátero da formação para a área da saúde: ensino, gestão, atenção e controle social. Physis: Revista de Saúde Coletiva, Rio de Janeiro, v. 14, n. 1, p. 41- 65, 2004

CECCIM, R. B.; MERHY, E. E. Um agir micropolítico e pedagógico intenso: a humanização entre laços e perspectivas. Interface Comunicação, Saúde, Educação, Botucatu, v. 13, supl. 1, p. 53142, 2009.

CORDÓN, J. A. Construção de uma agenda para a saúde bucal coletiva. Cadernos de Saúde Pública, Rio de Janeiro, v. 13, n. 3, p. 557-563, 1997. 
FREITAS, C. H. S. M. Dilemas no exercício profissional da Odontologia: a autonomia em questão. Interface - Comunicação, Saúde, Educação, Botucatu, v. 11, n. 21, p. 25-38, 2007.

GATTI, B. A. Grupo focal na pesquisa em Ciências Sociais e Humanas. Brasília: Liber Livro, 2005.

GUBA, E. G.; LINCON, Y. S. Fourth Generation Evaluation. Newbury Park: Sage Publications, 1989.

GUEDES, C. R.; NOGUEIRA, M. I.; CAMARGO JR., K. R. A subjetividade como anomalia: contribuições epistemológicas para a crítica do modelo biomédico. Ciência \& Saúde Coletiva, Rio de Janeiro, v. 11, n. 4, p. 1093-1103, 2006.

LUZ, M. Cultura contemporânea e medicinas alternativas: novos paradigmas em saúde no fim do século XX. Physis: Revista de Saúde Coletiva, Rio de Janeiro, v. 15, supl., p. 145-176, 2005.

MINAYO, M. C. S. O Desafio do Conhecimento: Metodologia Qualitativa em Saúde. 9. ed. São Paulo: Hucitec; Rio de Janeiro: ABRASCO, 2006.

PINHEIRO, R.; SILVA JUNIOR, A. G. Práticas avaliativas e as mediações com a integralidade na saúde: uma proposta para estudos de processos avaliativos na Atenção Básica. In.: PINHEIRO, R.; SILVA JUNIOR, A. G.; MATTOS, R. A. (Orgs.) Atenção básica e Integralidade: contribuições para estudos de práticas avaliativas em saúde. Rio de Janeiro: CEPESC-IMS/UERJ - ABRASCO, 2008. p. 17-41.

PINTO, C. A. G.; COELHO, I. B. Co-gestão do processo de trabalho e composição da agenda em uma equipe de atenção básica. In: CAMPOS, G. W. S.; GERRERO, A. V. P. Manual de práticas de atenção básica: saúde ampliada e compartilhada. São Paulo: Aderaldo e Rothschild, 2008. p. 323-345.
RONCALLI, A. G. Epidemiologia e Saúde Bucal Coletiva: um caminhar compartilhado. Ciência \& Saúde Coletiva, Rio de Janeiro, v. 11, n. 1, p. 105-114, 2006.

SANCHEZ, H. F.; DRUMOND, M. M.; VILAÇA, E. L. Adequação de recursos humanos ao PSF: percepção de formandos de dois modelos de formação acadêmica em odontologia. Ciência \& Saúde Coletiva, Rio de Janeiro, v. 13, n. 2, p. 523-531, 2008.

SCLIAR, M. História do conceito de saúde. Physis: Revista de Saúde Coletiva, Rio de Janeiro, v. 17, n. 1. p. 29-41, 2007.

SMEKE, E. M. L. Avaliação das atividades de Educação Permanente em Saúde no SUS-Campinas. 2007. Projeto de pesquisa aprovado no Edital 023/2006 do MCT-CNPq/MS-SCTIE-DECIT.

SOUZA, T. M. S.; RONCALLI, A. G. Saúde bucal no Programa Saúde da Família: uma avaliação do modelo assistencial. Caderno de Saúde Pública, Rio de Janeiro, v. 23, n. 11, p. 2727-2739, 2007.

SOUZA, E. C. F. Formação e trabalho em Odontologia: ampliar a clínica para construir uma nova cultura de cuidado em Saúde Bucal. In: CONFERÊNCIA ESTADUAL DE SAÚDE DO RIO GRANDE DO NORTE, 3., 2004. Anais... Natal: Conferência, 2004.

TEIXEIRA, M. C. B. A dimensão cuidadora do trabalho em equipe em saúde e sua contribuição para a odontologia. Ciência \& Saúde Coletiva, Rio de Janeiro, v. 11, n. 1, p. 45-51, 2006.

WESTPHAL, M. F; BÓGUS, C. M.; FARIA, M. M. Grupos focais: experiências precursoras em programas educativos em saúde no Brasil. Boletín de la Oficina Sanitaria Panamericana (OSP), Washington, v. 120, n. 6, p. 472-482, 1996.

Recebido para publicação em Agosto/2011

Versão final em Janeiro/2013

Conflito de interesse: Não houve

Suporte financeiro: inexistente 